Tropical Journal of Pharmaceutical Research November 2015; 14 (11): 1961-1968

ISSN: $1596-5996$ (print); 1596-9827 (electronic)

(c) Pharmacotherapy Group, Faculty of Pharmacy, University of Benin, Benin City, 300001 Nigeria.

All rights reserved.

Available online at http://www.tjpr.org

Original Research Article

http://dx.doi.org/10.4314/tjpr.v14i11.2

\title{
Fabrication and Evaluation of Rosuvastatin Calcium Fast- Disintegrating Tablets Using $\beta$-Cyclodextrin and Superdisintegrants
}

\author{
Rai Muhammad Sarfraz, Mahmood Ahmad*, Asif Mahmood, Muhammad Usman \\ Minhas and Ayesha Yaqoob \\ Faculty of Pharmacy and Alternative Medicines, the Islamia University of Bahawalpur, 63100, Bahawalpur, Punjab, Pakistan
}

*For correspondence: Email: ma786_786@yahoo.com; Tel: +923009682258; Fax: +92629255565

Received: 30 July 2015

Revised accepted: 6 October 2015

\begin{abstract}
Purpose: To formulate fast-disintegrating tablets (FDT) of rosuvastatin calcium (RST) using $\beta$ cyclodextrin (CD) and different superdisintegrants to enhance their solubility.

Methods: A total of 15 FDT formulations of RST were prepared using three different techniques. The FDTs were evaluated for micromeritic properties, as well as by Fourier transform infrared spectroscopy (FTIR), thermal analysis, disintegration time (DT), dissolution rate, powder $x$-ray diffraction (XRDP), scanning electron microscopy (SEM) and stability studies.

Results: XRDP showed that RST was changed from crystalline to amorphous form. SEM images revealed the presence of small microscopic pores that enhanced water penetration and provided rapid dissolution rate compared with the pure drug. There was maximum release of drug (99\%) from F4 formulation containing solid dispersion of RST, CD and superdisintegrants. DT and wetting time were 25 $s(p=0.032)$ and $33 s(p=0.023)$, respectively, for $F 4$ formulation. In vitro dispersion time was also lowest for F4 at $23 s(p=0.023)$. FTIR and DSC studies also confirmed complex formation of drug with $C D$ and superdisintegrants.

Conclusion: FDT is a suitable strategy to enhance the dissolution rate of RST and thus is an effective tool to improve bioavailability of poorly water soluble drugs.
\end{abstract}

Keywords: Solubility, $\beta$-cyclodextrin, Kyron, Polymer, Rosuvastatin, Fast-disintegrating tablets

Tropical Journal of Pharmaceutical Research is indexed by Science Citation Index (SciSearch), Scopus, International Pharmaceutical Abstract, Chemical Abstracts, Embase, Index Copernicus, EBSCO, African Index Medicus, JournalSeek, Journal Citation Reports/Science Edition, Directory of Open Access Journals (DOAJ), African Journal Online, Bioline International, Open-J-Gate and Pharmacy Abstracts

\section{INTRODUCTION}

Approximately $40 \%$ of newly developed drugs are poorly water soluble [1]. Poor solubility leads to poor dissolution in the gastrointestinal tract that results in variable oral absorption and bioavailability. Polymeric complexation can promote dissolution, absorption and ultimately bioavailability thereby reducing particle size or converting their nature from crystalline to amorphous [2 - 4]. Different techniques have been utilized in literature for this purpose like inclusion complexes, solid dispersions, hydrogel microparticles, microemulsions, microparticles, fast dissolving tablets, prodrug, milling, cocrystals, cryogenic, spray drying etc. [5-7].

Improved dissolution rate can be ascribed to (i) an increased solubility of the drug because of its amorphous state or small particle size (Kelvin's law) [8] (ii) an increasing surface area available for drug dissolution because of the small size of the drug particles [9] and (iii) an improved wetting of the drug caused by the hydrophilic carrier [10]. 
Various superdisintegrants like kyron T134, crospovidone, pregelatinized starch, sodium starch glycolate, croscarmellose sodium etc., along with hydrophilic carriers such as $\beta$ cyclodextrin etc., are used to enhance solubility and consequently, patient compliance [11-14]. Rosuvastatin calcium (RST), belongs to BCS class II drugs having low solubility and high permeability. It is poorly water-soluble 3-hydroxy3-methyl glutaryl CoA (HMG-CoA) reductase inhibitor. This enzyme catalyzes the conversion of HMG-CoA to mevalonate, which is an early and rate-limiting step in cholesterol biosynthesis. It is a potent lipid-lower ingredient used as hypolipidemic agent [15].

The objective of this study was to fabricate FDT's of rosuvastatin calcium using solid dispersion technique by polymer and disintegrants as well as their physical mixture.

\section{EXPERIMENTAL}

\section{Materials}

Rosuvastatin was obtained as gift sample from Getz pharmaceuticals Islamabad, Pakistan. Methanol and $\beta$-cyclodextrin were purchased from Sigma Aldrich Chemie $\mathrm{GmbH}$, Steinheim, Germany. Kyron T134, sodium starch glycolate and saccharine were obtained from Warrick pharmaceuticals Islamabad, Pakistan. Magnesium stearate and lactose were taken from chemical store of Department of Pharmacy, The Islamia University of Bahawalpur. All the chemicals used were relatively of high purity ( 97 - $99 \%$ ).

\section{Method}

Three different approaches of FDT's formulations were adapted; (1) solid dispersions composed of drug and carrier in which superdisintegrants were incorporated, (2) solid dispersions composed of drug and carrier physically mixed with superdisintegrants and (3) physical mixtures of drug, carrier and superdisintegrants.

F1 - F15 were prepared by slight modification of already used method [13]. Solution of drug was prepared in methanol while $\beta$-cyclodextrin and superdisintegrants were dissolved in water. Predetermined amounts of drug, $\beta$-cyclodextrin and superdisintegrants were weighed on an electronic weighing balance and dissolved in respective solvents. Both solutions were sonicated until clear solution was formed. These solutions were mixed and placed on hot plate stirrer to evaporate the solvent. Prepared solid dispersions were freeze dried for $24 \mathrm{~h}$ in lyophilizer (Alpha 1-4 LD Germany). All of these formulations were compressed into FDT's using $8 \mathrm{~mm}$ round flat beveled edge punches on a 10 station rotary tableting machine. A total of 15 formulations were prepared by varying concentration of carrier and superdisintegrants using these three different approaches as shown in Table 1 [13].

\section{FTIR spectroscopy}

FTIR spectra were obtained between 400 and $4000 \mathrm{~cm}^{-1}$ by using IR spectrophotometer (Bruker Tensar 27 Germany) to confirm complex formation. FTIR spectra of individual ingredients and tablets were taken [16].

\section{Thermal analysis}

DSC and TGA analysis of prepared FDT's and all ingredients were taken to determine stability of ingredients in prepared tablets. DSC (Q600 TA USA) was done by heating samples from ambient to $400{ }^{\circ} \mathrm{C}$ at a heating rate of $10^{\circ} \mathrm{C} / \mathrm{min}$ under nitrogen atmosphere at a flow rate of 10 $\mathrm{ml} / \mathrm{min}[16]$.

Table 1: Composition of fast disintegrating tablets

\begin{tabular}{|c|c|c|c|c|c|c|c|c|c|c|c|c|c|c|c|}
\hline \multirow[t]{2}{*}{ Ingredients (mg) } & \multicolumn{5}{|c|}{$\begin{array}{l}\text { FDT's containing solid } \\
\text { dispersions of drug, } \\
\text { carrier and } \\
\text { superdisintegrants (F1- } \\
\text { F5) }\end{array}$} & \multicolumn{5}{|c|}{$\begin{array}{l}\text { FDT's containing solid } \\
\text { dispersions of drug and } \\
\text { carrier physically mixed } \\
\text { with superdisintegrants } \\
\text { (F6-F10) }\end{array}$} & \multicolumn{5}{|c|}{$\begin{array}{l}\text { FDT's containing physical } \\
\text { mixture of drug, carrier and } \\
\text { superdisintegrants (F11-F15) }\end{array}$} \\
\hline & $F 1$ & F2 & F3 & $F 4$ & F5 & F6 & F7 & F8 & F9 & F10 & F11 & $F 12$ & $F 13$ & $F 14$ & F15 \\
\hline Rosuvastatin $\mathrm{Ca}^{2+}$ & 20 & 20 & 20 & 20 & 20 & 20 & 20 & 20 & 20 & 20 & 20 & 20 & 20 & 20 & 20 \\
\hline Kyron- $T_{134}$ & 8 & 16 & - & 16 & - & 8 & 16 & - & 16 & - & 8 & 16 & - & 16 & - \\
\hline Sodium starch glycolate & 8 & - & 16 & - & 16 & 8 & - & 16 & - & 16 & 8 & - & 16 & - & 16 \\
\hline$\beta$-cyclodextrin & 60 & 60 & 60 & 80 & 80 & 60 & 60 & 60 & 80 & 80 & 60 & 60 & 60 & 80 & 80 \\
\hline Mg-Stearate & 4 & 4 & 4 & 4 & 4 & 4 & 4 & 4 & 4 & 4 & 4 & 4 & 4 & 4 & 4 \\
\hline Talc & 4 & 4 & 4 & 4 & 4 & 4 & 4 & 4 & 4 & 4 & 4 & 4 & 4 & 4 & 4 \\
\hline Lactose & 85 & 85 & 85 & 65 & 65 & 85 & 85 & 85 & 65 & 65 & 85 & 85 & 85 & 65 & 65 \\
\hline Orange flavor & 5 & 5 & 5 & 5 & 5 & 5 & 5 & 5 & 5 & 5 & 5 & 5 & 5 & 5 & 5 \\
\hline Saccharin sodium & 6 & 6 & 6 & 6 & 6 & 6 & 6 & 6 & 6 & 6 & 6 & 6 & 6 & 6 & 6 \\
\hline
\end{tabular}




\section{Friability}

Friability of tablets was determined using Roche friabilator (Pharma Test, Germany). Twenty tablets were weighed and placed in the drum of the friabilator at a speed of $25 \mathrm{rpm}$. Tablets were allowed to revolve, fall from height of six inches for $4 \mathrm{~min}$. Then tablets were de-dusted using muslin cloth and re-weighed. Then friability was measured by calculating \% weight loss of 20 FDT's [16].

\section{Tablet disintegration}

Tablet disintegration apparatus was used. Six tablets were taken and placed individually in tubes and properly covered. Temperature of medium was maintained at $37 \pm 2{ }^{\circ} \mathrm{C}$ and timely monitored by thermometer. Time taken by the tablet to disintegrate completely was noted [16].

\section{Wetting time}

A circular tissue paper having diameter $8 \mathrm{~cm}$ folded twice was placed in the petri dish. $10 \mathrm{ml}$ of phosphate buffer solution of $\mathrm{pH} 6.80$ used as saliva was taken in petri dish. Single tablet was placed on tissue paper and time for complete wetting was noted [17].

\section{Dissolution study}

Dissolution studies of FDTs were performed using USP type-II apparatus. Speed of apparatus was set at $50 \mathrm{rpm}, 900 \mathrm{ml}$ of phosphate buffer solution of $\mathrm{pH} 6.80$ was taken as dissolution medium in each vessel of the apparatus. A single tablet was placed in each vessel and temperature was kept at $37 \pm 0.5{ }^{\circ} \mathrm{C}$. Samples were removed from each vessel at regular intervals and was replaced by equal volume of freshly prepared media. Absorbance was measured by using UV/Vis spectrophotometer (UV 1700, Shimadzu, Japan) at $243 \mathrm{~nm}$ [18].

\section{In vitro dispersion time}

About $6 \mathrm{ml}$ phosphate buffer of $\mathrm{pH} 6.80$ was taken in a beaker of $10 \mathrm{~mL}$ capacity. Tablet was placed in beaker and time required for complete dispersion of tablet was noted. Experiment was performed thrice for each formulation.

\section{Water absorption ratio}

Six milliliters of water was taken in a Petri dish of internal diameter $6.50 \mathrm{~cm}$. A piece of tissue paper folded twice was placed in the petri dish. A tablet was weighed before placing onto tissue paper in petri dish and time taken by tablet for complete wetting was noted. Wetted tablet was reweighed and water absorption ratio was calculated [19].

\section{X-ray powder diffraction (XRPD)}

Samples were analyzed using an X'Pert PROMPD diffractometer (PANalytical, Almelo, the Netherlands) with a copper anode $(\mathrm{Cu} \mathrm{Ka}$ radiation, $\mathrm{k}=0.15405 \mathrm{~nm}, 40 \mathrm{kV}, 40 \mathrm{~mA}$ ). The diffraction pattern was measured with a step size of 0.008 and a dwell time of $45 \mathrm{~S}$ at each step between $4^{\circ}$ and $50^{\circ}$ for $2 \mathrm{~h}$ at ambient temperature [20].

\section{Scanning electron microscopy}

For SEM measurements to describe the shape and surface morphology as well as to check porosity on tablet surfaces that are helpful in rapid release of drug, rosuvastatin based FDT's were attached on metal stubs using doublesided adhesive tape, dried in a vacuum chamber, they were then sputter-coated with a gold layer of $10 \mathrm{~nm}$ thick and viewed under high resolution SEM (JSM-840, Joel Instruments, Tokyo, Japan) [21].

\section{Stability studies}

The stability studies of FDT's were performed for three best formulations for a period of six months according to $\mathrm{ICH}$ (international conference on harmonization) guidelines. After period of 3 and 6 months tablets were re-evaluated for drug content and other parameters. Studies were performed under the following temperature and humidity conditions $37 \pm 1^{\circ} \mathrm{C}, 40 \pm 1^{\circ} \mathrm{C}, 50 \pm 1$ ${ }^{\circ} \mathrm{C}$ and $\mathrm{RH} 75 \pm 5 \%$ [14].

\section{Statistical analysis}

SPSS $18^{\circledR}$ software was used to analyze the data. All results are expressed as mean \pm standard deviation (SD). The data for various formulations were compared by one-way analysis of variance (ANOVA). $P<0.05$ was considered to be statistically significant.

\section{RESULTS}

Powder for FDT's was first evaluated for rheological parameters. Results of these parameters were compared with pharmacopeial standards as shown in (Table 2). Results indicated that excipients combination was suitable for compression into FDT's and all ingredients were mixed properly before compression [22]. 
FTIR spectra showed that characteristic peeks were present at $3337.90 \mathrm{~cm}^{-1}, 2968.23 \mathrm{~cm}^{-1}$ and $1435.48 \mathrm{~cm}^{-1}$ corresponding to cyclic amines, C$\mathrm{H}$ stretching, $\mathrm{C}=\mathrm{O}$ stretching, $\mathrm{O}-\mathrm{H}$ bending. These were similar to what has been previously reported in monograph for rosuvastatin [15]. Thermal analysis was performed to check the stability of complexes formed between drug, carrier and superdisintegrants. DSC thermograms of rosuvastatin alone, physical mixture of drug, carrier and superdisintegrants as well as of prepared FDT's were also taken. There was present a sharp endothermic peak at $126{ }^{\circ} \mathrm{C}$ in DSC thermogram of pure drug and of physical mixture as well.

Table 2: Bulk density, tapped density, angle of Repose, Hausner's ratio and Carr's index

\begin{tabular}{llllll}
\hline Code & $\begin{array}{l}\text { Bulk } \\
\text { density }(\mathbf{g} / \mathbf{m l})\end{array}$ & $\begin{array}{l}\text { Tapped } \\
\text { density }(\mathbf{g} / \mathbf{m l})\end{array}$ & $\begin{array}{l}\text { Angle of } \\
\text { repose } \\
(\boldsymbol{\Theta})\end{array}$ & $\begin{array}{l}\text { Hausner's } \\
\text { ratio }\end{array}$ & $\begin{array}{l}\text { Carr's } \\
\text { index } \\
(\%)\end{array}$ \\
\hline F1 & 0.629 & 0.737 & 23.60 & 1.17 & 15.75 \\
F2 & 0.637 & 0.729 & 21.50 & 1.14 & 16.50 \\
F3 & 0.631 & 0.733 & 23.80 & 1.16 & 14.97 \\
F4 & 0.619 & 0.719 & 25.40 & 1.16 & 16.45 \\
F5 & 0.621 & 0.727 & 24.50 & 1.17 & 15.50 \\
F6 & 0.609 & 0.719 & 22.60 & 1.18 & 16.40 \\
F7 & 0.629 & 0.723 & 24.90 & 1.14 & 15.98 \\
F8 & 0.623 & 0.751 & 24.70 & 1.20 & 16.57 \\
F9 & 0.621 & 0.730 & 23.80 & 1.17 & 15.82 \\
F10 & 0.597 & 0.713 & 26.10 & 1.19 & 15.80 \\
F11 & 0.640 & 0.727 & 24.50 & 1.13 & 17.26 \\
F12 & 0.623 & 0.727 & 24.80 & 1.16 & 15.28 \\
F13 & 0.623 & 0.738 & 24.70 & 1.18 & 16.90 \\
F14 & 0.639 & 0.746 & 25.80 & 1.16 & 14.50 \\
F15 & 0.609 & 0.713 & 25.60 & 1.17 & 16.80 \\
\hline
\end{tabular}

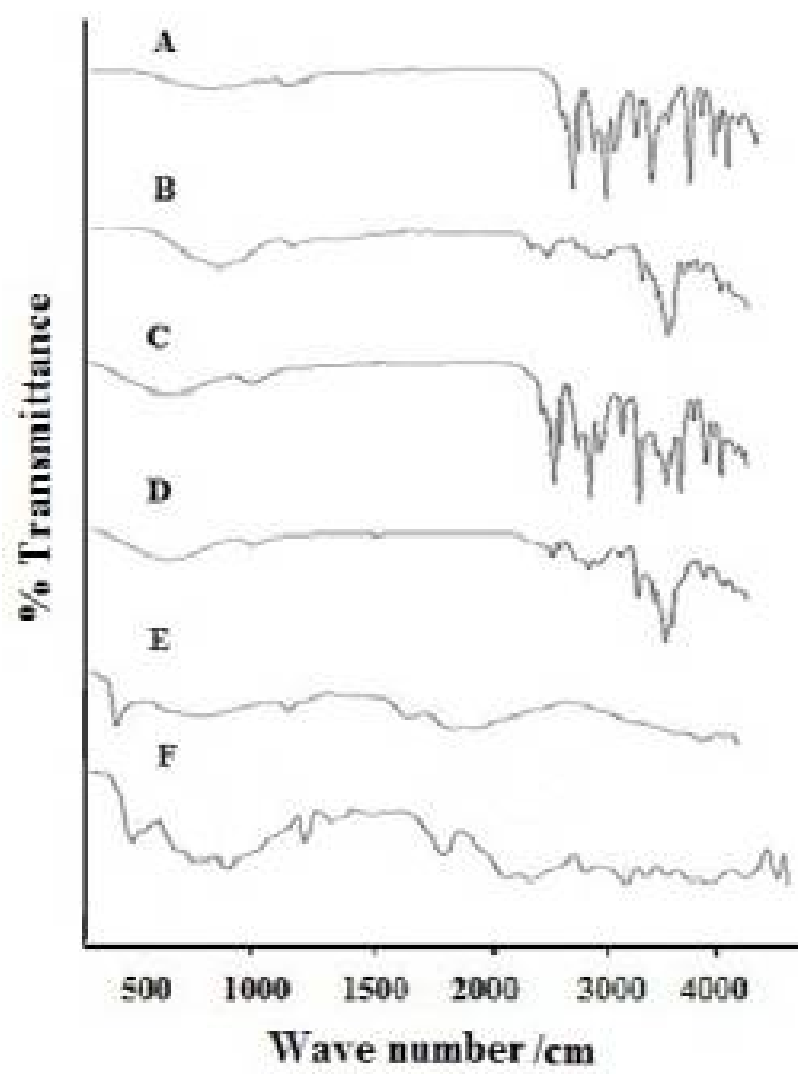

Figure 1: FTIR spectra of $(A)$ rosuvastatin calcium (B) $\beta$-cyclodextrin (C) FDT's containing physical mixture (D) FDT's containing solid dispersion (E) kyron T134 (F) sodium starch glycolate.

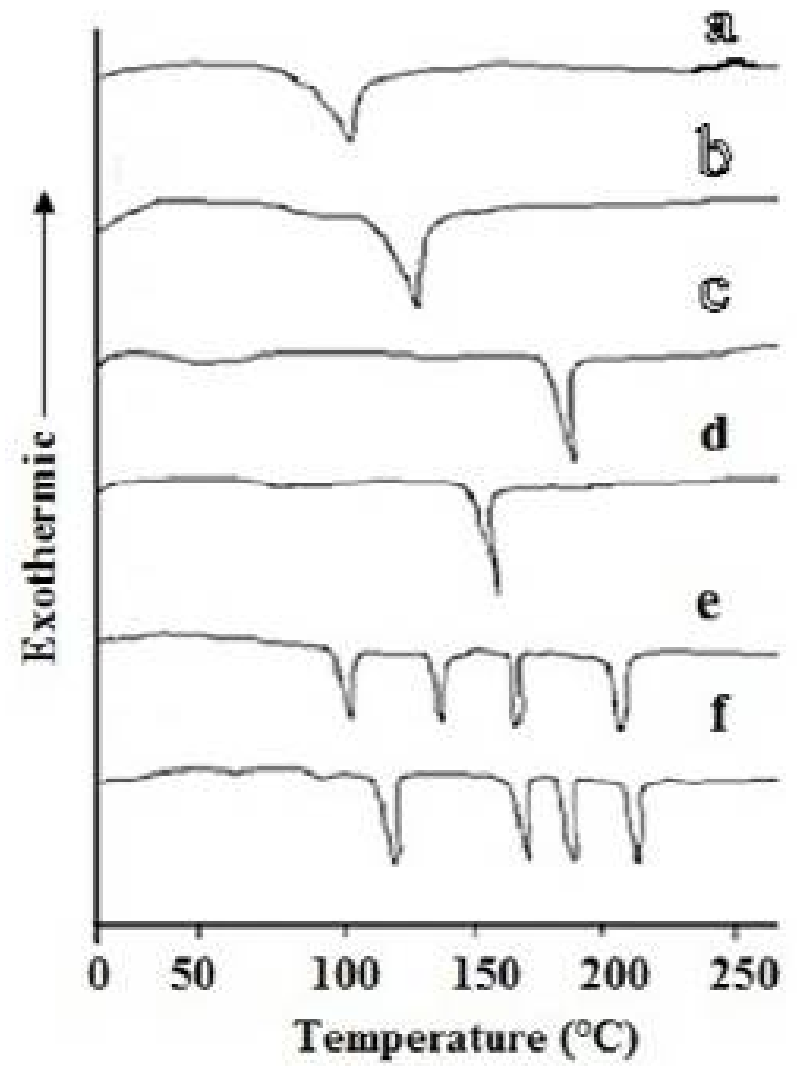

Figure 2: DSC spectra of (a) $\beta$ - cyclodextrin (b) rosuvastatin calcium (c) kyron $\mathrm{T}_{134}$ (d) sodium starch glycolate (e) FDT physical mixture (f) FDT solid dispersion 
XRD pattern of pure drug showed sharp diffraction peaks at $2 \theta$ values of $16.04^{\circ}$, $22.45^{\circ}$, and $34.3^{\circ}$ while FDT's showed no such characteristics peaks at $2 \theta$ (Fig 3). Morphology of FDT's was determined by using scanning electron microscopy. SEM images had shown that pores had been created on surface of tablets (Fig 4). Pores have favored influx of water inside of tablets to fasten the release of drug from the tablets and ultimately solubility was enhanced. Similar findings were observed by Inayat et al [21].

Results of weight variation hardness, thickness, Friability, disintegration time and wetting time for all formulations were present within pharmacopeial limits as shown in Table 2. Formulations based on solid dispersions exhibited better hardness results as compared to physical mixture [23].

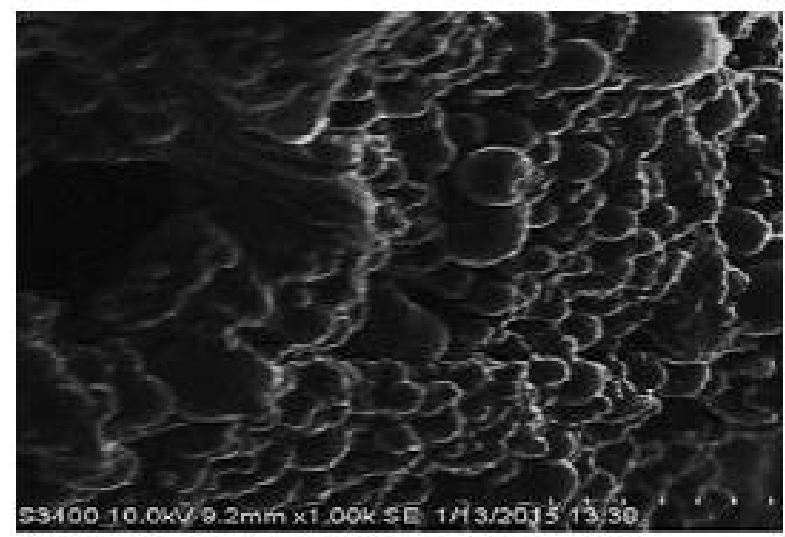

Figure 4: SEM image of formulation F4

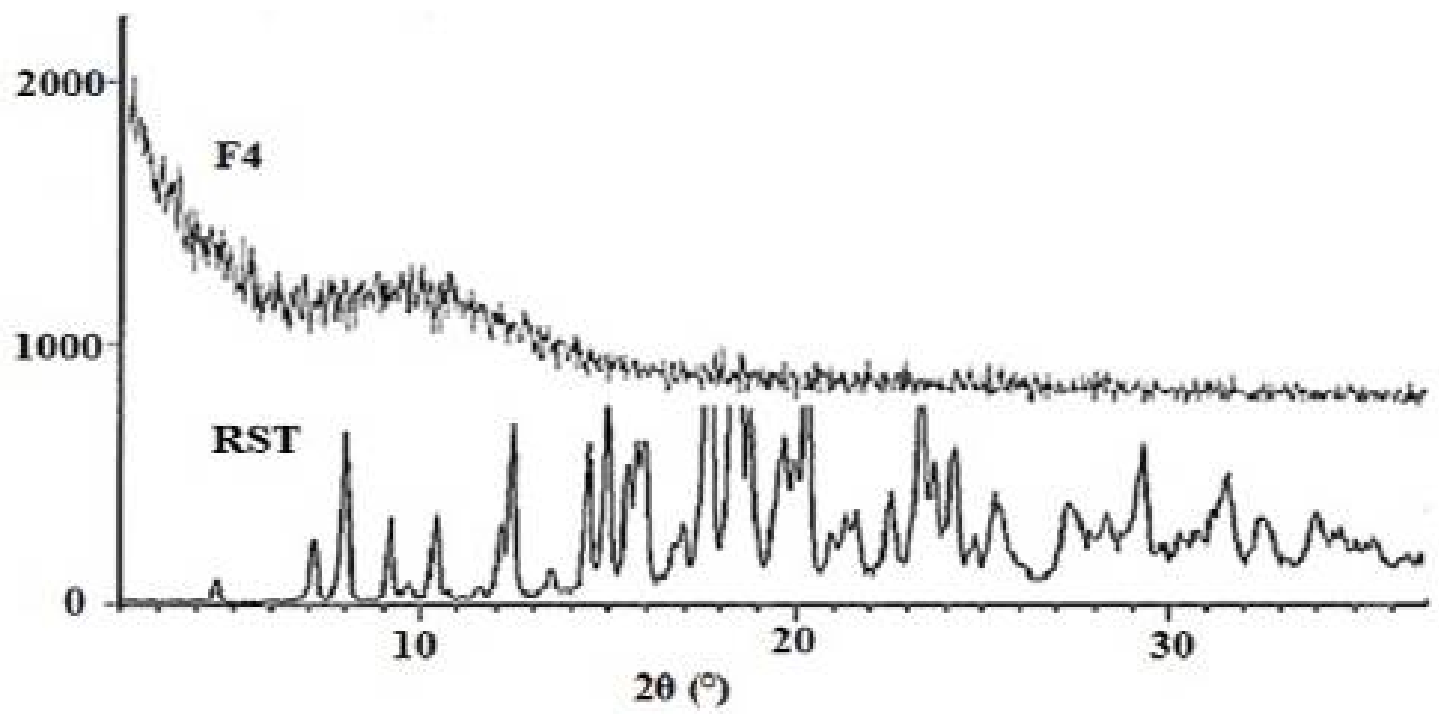

Figure 3: X-ray diffractogram of rosuvastatin calcium (RST) alone and formulation F4

Table 3: Weight variation, hardness, thickness, friability, disintegration time and wetting time

\begin{tabular}{|c|c|c|c|c|c|c|}
\hline Code & $\begin{array}{l}\text { Weight } \\
\text { variation } \\
(\mathrm{mg})\end{array}$ & $\begin{array}{c}\text { Hardness( } \\
\mathrm{Kg} / \mathrm{cm}^{2} \text { ) }\end{array}$ & $\begin{array}{l}\text { Thickness } \\
(\mathrm{mm})\end{array}$ & $\begin{array}{c}\text { Friability* } \\
(\%)\end{array}$ & $\begin{array}{c}\text { Disintegration }{ }^{\star} t i \\
\text { me } \\
\text { (Sec) }\end{array}$ & $\begin{array}{l}\text { Wetting }^{*} \\
\text { time } \\
\text { (Sec) }\end{array}$ \\
\hline $\mathrm{F} 1$ & 198.90 & 3.30 & 3.20 & $0.654 \pm 0.00$ & $43 \pm 1.15$ & $55 \pm 1.25$ \\
\hline $\mathrm{F} 2$ & 197.50 & 3.20 & 3.25 & $0.605 \pm 0.02$ & $34 \pm 1.15$ & $43 \pm 1.50$ \\
\hline F3 & 198.87 & 3.40 & 3.10 & $0.590 \pm 0.01$ & $39 \pm 3.46$ & $48 \pm 1.61$ \\
\hline F4 & 199.80 & 3.30 & 3.30 & $0.502 \pm 0.02$ & $25 \pm 1.15$ & $33 \pm 1.58$ \\
\hline F5 & 199.50 & 3.10 & 3.40 & $0.498 \pm 0.01$ & $29 \pm 1.08$ & $37 \pm 0.73$ \\
\hline F6 & 198.54 & 3.40 & 2.99 & $0.630 \pm 0.02$ & $54 \pm 2.15$ & $63 \pm 2.18$ \\
\hline F7 & 197.75 & 3.20 & 3.35 & $0.580 \pm 0.01$ & $45 \pm 1.25$ & $54 \pm 1.25$ \\
\hline F8 & 199.80 & 3.50 & 3.02 & $0.530 \pm 0.01$ & $50 \pm 1.70$ & $59 \pm 1.50$ \\
\hline F9 & 195.72 & 3.30 & 3.15 & $0.520 \pm 0.02$ & $37 \pm 2.21$ & $41 \pm 1.20$ \\
\hline $\mathrm{F} 10$ & 197.60 & 3.60 & 3.20 & $0.630 \pm 0.03$ & $42 \pm 1.15$ & $46 \pm 1.70$ \\
\hline F11 & 198.26 & 3.20 & 3.10 & $0.580 \pm 0.01$ & $66 \pm 1.25$ & $75 \pm 1.25$ \\
\hline $\mathrm{F} 12$ & 197.85 & 3.60 & 3.38 & $0.480 \pm 0.00$ & $54 \pm 1.10$ & $68 \pm 1.60$ \\
\hline F13 & 198.35 & 3.40 & 3.20 & $0.540 \pm 0.02$ & $60 \pm 1.15$ & $71 \pm 1.80$ \\
\hline $\mathrm{F} 14$ & 199.40 & 3.50 & 3.28 & $0.590 \pm 0.02$ & $48 \pm 1.15$ & $53 \pm 1.50$ \\
\hline $\mathrm{F} 15$ & 197.60 & 3.40 & 3.08 & $0.480 \pm 0.02$ & $52 \pm 1.83$ & $57 \pm 2.30$ \\
\hline
\end{tabular}

${ }^{*}$ Mean $\pm S D(n=3)$ 
Friability of all the formulations was less than 0.8 $\%$ which suggested that tablets had good mechanical strength. Statistically results of friability were tested by using one way ANOVA. Results of ANOVA between the groups show $p$ value of 0.025 which was less than 0.05 indicating significance. Disintegration time for FDT's generally considered good if it is $<1 \mathrm{~min}$ (Table 3) [14]. Rapid uptake of water can cause swelling which ultimately produce bursting effect. This results in fast release of drug into the surrounding environment and hence solubility of loaded drug was enhanced. Similar to wetting time it was also lowest for F4 formulation [24].

All formulations were evaluated for in vitro dispersion time and it was found lowest (23 s) for F4. Dispersion time was graded like FDT's containing solid dispersion of drug, carrier and disintegrant > FDT's containing solid dispersion of drug and carrier physically mixed with disintegrant > FDT's containing physical mixture of drug, carrier and disintegrant as shown in Table 4. $P$-value was 0.018 for dispersion time.

Formulation F4 absorbed water approximately double its original weight as shown in Table $4(p$ $=0.011$ ), which indicates that the concentration of $\beta$-cyclodextrin and disintegrants affected tablet disintegration.

Dissolution studies have shown a marked difference in release of rosuvastatin from the commercially available tablets and FDT's. Maximum concentration of drug was released from FDT's within $15 \mathrm{~min}$ as compared to commercially available tablets. There was maximum release of drug in formulation $\mathrm{F} 4$ that was $99 \%$ in 15 min (Fig 5).

Table 4: Wetting volume, dispersion time, $\mathrm{pH}$ of tablet solution and water absorption ratio

\begin{tabular}{lcccc}
\hline Code & $\begin{array}{c}\text { Wetting } \\
\text { volume } \\
(\mathbf{m l})\end{array}$ & $\begin{array}{c}\text { Dispersion* } \\
\text { time }(\mathbf{s})\end{array}$ & $\begin{array}{c}\text { pH of tablet } \\
\text { solution }\end{array}$ & $\begin{array}{c}\text { Water } \\
\text { absorption } \\
\text { ratio }\end{array}$ \\
\hline F1 & $21 \pm 2.05$ & $39 \pm 1.73$ & 7.10 & $1.70 \pm 0.02$ \\
F2 & $14 \pm 1.10$ & $30 \pm 1.15$ & 7.20 & $1.80 \pm 0.06$ \\
F3 & $17 \pm 1.25$ & $33 \pm 1.15$ & 7.00 & $1.80 \pm 0.01$ \\
F4 & $09 \pm 1.58$ & $23 \pm 0.58$ & 6.80 & $2.20 \pm 0.02$ \\
F5 & $11 \pm 2.18$ & $26 \pm 1.58$ & 7.00 & $2.00 \pm 0.04$ \\
F6 & $23 \pm 1.58$ & $42 \pm 0.58$ & 7.10 & $1.60 \pm 0.05$ \\
F7 & $17 \pm 1.15$ & $33 \pm 1.15$ & 7.00 & $1.70 \pm 0.08$ \\
F8 & $20 \pm 1.00$ & $37 \pm 1.73$ & 7.20 & $1.60 \pm 0.06$ \\
F9 & $12 \pm 1.25$ & $25 \pm 1.15$ & 6.80 & $2.00 \pm 0.23$ \\
F10 & $14 \pm 1.15$ & $29 \pm 1.25$ & 6.80 & $1.90 \pm 0.05$ \\
F11 & $26 \pm 1.78$ & $46 \pm 1.73$ & 7.00 & $1.50 \pm 0.23$ \\
F12 & $18 \pm 1.80$ & $38 \pm 1.15$ & 7.20 & $1.60 \pm 0.00$ \\
F13 & $24 \pm 1.50$ & $42 \pm 2.18$ & 7.00 & $1.55 \pm 0.06$ \\
F14 & $16 \pm 0.80$ & $30 \pm 0.58$ & 6.80 & $1.90 \pm 0.04$ \\
F15 & $19 \pm 1.00$ & $35 \pm 1.73$ & 7.20 & $1.80 \pm 0.02$ \\
\hline FI
\end{tabular}

*Mean $\pm S D(n=3)$

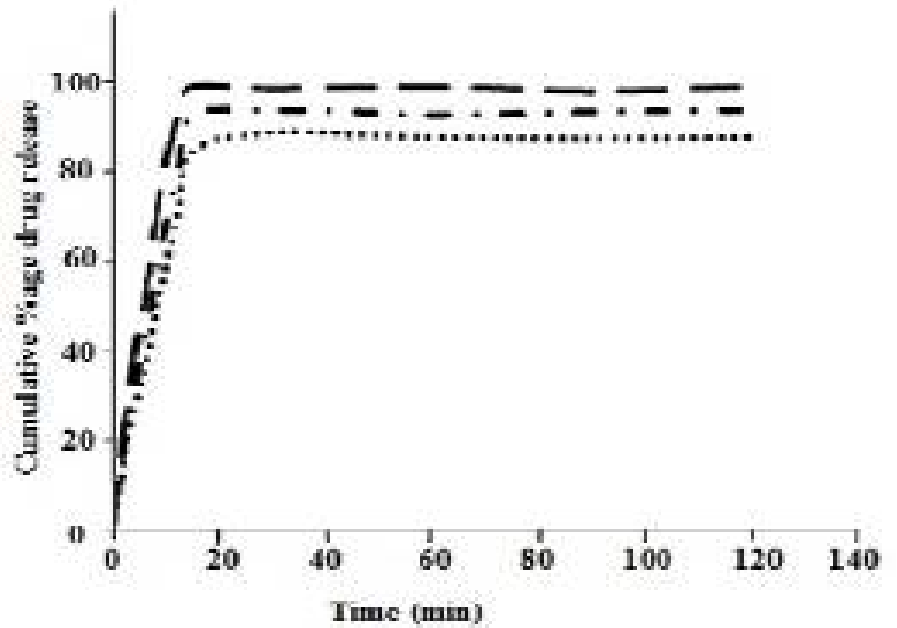

Figure 5: Drug release curve of F4 (-), F9 (*-) and F14 (****) at pH 6.8 
Stability studies of three best formulations were conducted for six month period. Tablets were evaluated for different parameters. Results had indicated that there was no significant difference occurred in drug content and in vitro dispersion time at the end of 6 months.

\section{DISCUSSION}

Flow properties are very important for powder or particulate material to compress into tablets. Materials that do not have good flow properties are difficult to compress into tablets and ultimately leads to improper mixing of drug with other ingredients as well as can cause other compression problems.

FTIR spectra of pure drug indicate characteristics peaks were present at 3337.90, 2968.23 and $1435.48 \mathrm{~cm}^{-1}$ as shown in (Fig 1). Similar peaks were present in physical mixture of drug, superdisintegrants and $\beta$-cyclodextrin. It confirmed that, no interaction was present between drug and excipients. But FTIR spectra of our formulations had shown that characteristic peak of rosuvastatin was shifted from 3337.90 to $3127.13 \mathrm{~cm}^{-1}$ and complete absence of characteristic peak that was present at 1435.48 $\mathrm{cm}^{-1}$ due to $\mathrm{O}-\mathrm{H}$ bending. These findings had supported that there was complex formation between drug and polymer in solid dispersions. Our results were in compliance of study conducted by Pavan et al [25].

DSC studies depicts no interaction between drug and polymer. In thermogram of FDT's characteristic peak of rosuvastatin disappeared from $126^{\circ} \mathrm{C}$ and shifted to higher temperature of $170{ }^{\circ} \mathrm{C}$ (Fig 2). This shifting of peaks was due to the formation of solid complex between drug, carrier and superdisintegrants. Mura et al also found in their studies that disappearance or shifting of peaks confirmed that formation of complex [26].

Hardness generally indicates that tablets are able to bear stress during handling, storage and transportation. A linear relationship exists between tablet hardness and disintegration time (DT). The absence of characteristics peaks in PXRD formulation indicated that drug had converted from crystalline to amorphous form. As a result solubility of rosuvastatin was enhanced in FDT's prepared by using $\beta$-cyclodextrin and superdisintegrants because amorphous forms are more soluble as compared to crystalline form. Similar results were obtained by Pavan et al in their study [25].
Overall values of drug release were present between 93-99 \% that were far better than commercially available tablets. These may also be due to increase in pores on surface of tablets as shown in SEM image (Fig 4) [27]. Based on the findings of dissolution studies, SEM, FTIR, DSC, PXRD of various formulations we found that $\beta$-cyclodextrin had influenced solubility of rosuvastatin used as model drug in this study. As a result in vitro dissolution was enhanced. When dissolution results of various formulations were compared based on method of preparation then it was found that FDT's containing solid dispersions had better release rate than FDT's containing physical mixture of same concentration of all constituents. Similar findings were obtained by Manjil et al [28].

\section{CONCLUSION}

Rosuvastatin calcium FDTs were successfully prepared in this study for enhanced solubility of the drug. The techniques used should also be suitable for enhancement of the dissolution profile of other poorly water-soluble drugs.

\section{ACKNOWLEDGEMENT}

Authors are highly grateful To Higher Education Commission of Pakistan (HEC) for providing financial support for this study.

\section{REFERENCES}

1. Keralia RA, Soni TG, Thakkar VT, Gandhi TR, Patel RC. Formulation and physical characterization of microcrystals for dissolution rate enhancement of tolbutamide. Int J Res Pharma Sci 2010; 1: 69-77.

2. Craig DQM. The mechanisms of drug release from solid dispersions in water-soluble polymers. Int $J$ Pharma 2002; 231: 131-144.

3. Ford J.L. The current status of solid dispersions. Pharm Acta Helv 1986; 61: 69-88.

4. Leuner C. Dressman J. Improving drug solubility for oral delivery using solid dispersions. Eur $J$ Pharm Biopharm 2000; 50: 47-60.

5. Dai WG, Dong LC, Song YQ. Nanosizing of a drug/carrageenan complex to increase solubility and dissolution rate. Int J Pharm 2007; 342: 201-207.

6. Purvis $T$, Vaughn JM, Rogers TL, Chen $X$, Overhoff $K A$, Sinswat $P$, Hu J, McConville JT, Johnston KP, Williams RO. Cryogenic liquids, nanoparticles, and microencapsulation. Int J Pharm 2006; 324: 43-50.

7. Chow AHL, Hsia CK, Gordon JD, Young JWM, VarghaButler El. Assessment of wettability and its relationship to the intrinsic dissolution rate of doped phenytoin crystals. Int J Pharm 1995; 126: 21-28. 
8. Lee JK, Grace KA, Taylor AJ. Effect of a pharmacy care program on medication adherence and persistence, blood pressure, and low-density lipoprotein cholesterol: a randomized controlled trial. JAMA 2006; 296: 2563-2571.

9. Madgalkar AR, Bhalekar MR, Padalkar RR. Formulation design and optimization of novel taste masked mouth dissolving tablets of tramadol having adequate mechanical strength. AAPS Pharm Sci Tech 2009; 10: $574-581$.

10. Rahman Z, Siddiqui A, Khan MA. Orally disintegrating tablet of novel salt of antiepileptic drug: Formulation strategy and evaluation. Eur J Pharma Biopharma 2013; 85: 1300-1309

11. Padala KP, Hinners CK, Padala PR. Mirtazapine therapy for dysgeusia in an elderly patient prim care companion. J Clin Psychiatry 2006; 8: 178-180.

12. Rockville MD. Food and Drug Administration Draft Guidance for Industry, Orally Disintegrating Tablets, Maryland press, USA, 2003.

13. Srinarong P, Faber JH, Visser MR, Hinrichs WLJ, Frijlink HW. Strongly enhanced dissolution rate of fenofibrate solid dispersion tablets by incorporation of superdisintegrants. Eur J Pharma Biopharma 2009; 73: 154-161.

14. Sarfraz RM, Khan HU, Mahmood A, Ahmad M, Maheen $S$, Sher M. Formulation and evaluation of mouth disintegrating tablets of atenolol and atorvastatin. Ind J Pharm Sci 2015; 77: 83-90.

15. Schachter M. Chemical, pharmacokinetic and pharmacodynamic properties of statins: an update. Funda Clin Pharmacol 2005; 19: 117-125.

16. Sarfraz RM, Ahmad M, Mahmood A, Khan HU, Sher M, Maheen S, Bashir I, lqbal A, Ahsan H. Int J Bio Pharm Alli Sci 2014; 3: 941-951.

17. Mahmood A, Ahmad M, Sarfraz RM, Minhas MU, Yaqoob A. Development and in vitro evaluation of acyclovir rapid dissolving tablets: a solubility and bioavailability enhancement study. Lat Am J Pharm 2015; 34: 17011709
18. Battue SK, Repay MA, Maunder S, Rio MY. Formulation and evaluation of rapidly disintegrating tablet fenoverine tablets: effect of superdisintegrants. Drug Dev Ind Pharm 2007; 33: 1225-1232.

19. Gohel MC, Bansal G, Bhatt N. Formulation and evaluation of orodispersible taste masked tablets of Famotidine. Pharma Boil World 2005; 3: 75-80.

20. Razali S, Wong TW. Design of superdisintegrant- and effervescent agent-less dispersible fast-release melt pellets. Powder Technol 2013; 235: 289-298

21. Inayat BP, Prakash RS, Pritish K. Formulation design and optimization of novel mouth dissolving tablets for venlafaxine hydrochloride using sublimation technique. J Pharm Res 2013; 6: 593-598.

22. Singh KS, Sameer AA. Development and characterization of sublingual tablet of Lisinopril. Asian Pac J Trop Biomed 2012; 2: S1711-S1719.

23. Marais AF, Song M, deVilliers MM. Effect of compression force, humidity and disintegrant concentration on the disintegration and dissolution of directly compressed furosemide tablets using croscarmellose sodium as disintegrant. Trop J Pharm Res 2003; 2: 128-135.

24. Biswajit B, Joshi V. Formulation and evaluation of orodispersible tablets of Amlodipine Besylate. Int $\mathrm{J}$ Pharm Technol 2011; 3: 3745-3766.

25. Pavan, SS, Karimunnisa, Chaudhari PD. Application of Liquisolid Technology for Enhancing Solubility and Dissolution of Rosuvastatin. Adv Pharm Bull 2014; 4: 197-204.

26. Gubbi S, Jarag R, Liquisolid Technique for enhancement of dissolution properties of bromhexine hydrochloride. Res J Pharm Tech 2009; 2: 382-386.

27. Lua Y, Sturekb M, Parka K. Microparticles produced by the hydrogel template method for sustained drug delivery. Int J Pharm 2014; 461: 258-269.

28. Patel M, Tekade A, Gattani S, Surana S. Solubility enhancement of lovastatin by modified locust bean gum using solid dispersion techniques. AAPS Pharm Sci Tech 2008; 9: 1262-1269. 